\title{
Risk factors and HIV infection among patients diagnosed with deep vein thrombosis at a regional/tertiary hospital in Kimberley, South Africa
}

\author{
FK Mampuya ${ }^{a}$, WJ Steinberg ${ }^{a *}$ (D) and JE Raubenheimer ${ }^{b}$ iD \\ ${ }^{a}$ Faculty of Health Sciences, Department of Family Medicine, University of the Free Sate, Bloemfontein, South Africa \\ ${ }^{b}$ Faculty of Health Sciences, Department of Biostatistics, University of the Free Sate, Bloemfontein, South Africa \\ *Corresponding author, email: steinbergwj@ufs.ac.za
}

Background: Common risk factors for developing deep vein thrombosis (DVT) are prolonged immobilisation, surgery, leg trauma or fracture, pregnancy, hormone therapy, heart failure, cancer, obesity, age, and smoking. The incidence of DVT in HIV-infected patients shows a two- to tenfold increase in comparison with a healthy population of similar age. This retrospective descriptive study evaluated the presence of risk factors for DVT and the prevalence of HIV infection in patients with confirmed DVT treated at Kimberley Hospital Complex, a regional/tertiary hospital in the Northern Cape Province, South Africa, from January 2010 to December 2014.

Methods: Patients were identified from the ultrasound register from the Radiology Department, and all adult patients with Doppler-proven DVT during the five-year period were included in the study. The data were extracted from the patient files and captured on data sheets.

Results: Of the 852 patients included in the study, most were female ( $n=536,62.9 \%$ ). The median age was 45 years (range 5-94 years, interquartile range 34-58 years). More than half ( $n=443,52.0 \%)$ of the patients were HIV-positive, 333 (39.1\%) HIVnegative, while 76 (8.9\%) did not have a known HIV status. The most common association with DVT was HIV infection (52.0\%) followed by tuberculosis (12.4\%), cancer $(10.9 \%)$, and smoking $(9.0 \%)$. The least common risk factors were long-distance travel $(0.4 \%)$ and thrombophilia (0.4\%). The left popliteal vein was the most frequently affected site (42.0\%) followed by left superficial femoral vein $(40.8 \%)$ and left common femoral vein (34.7\%). The location of the DVT was not associated with the HIV status of the patients.

Conclusion: At Kimberley Hospital Complex, the most common risk factor in patients presenting with DVT was HIV infection, with more than half of the patients being HIV-positive. Other risk factors included tuberculosis, cancer and smoking.

Keywords: adult patients, cancer, doppler-proven DVT, DVT location, smoking, tuberculosis

\section{Introduction}

Venous thrombosis is the process of a clot or thrombus formation within the veins. This predominantly occurs in the leg vessels resulting in deep vein thrombosis (DVT), or in the lungs resulting in a pulmonary embolus. This is collectively referred to as venous thromboembolism (VTE) and is associated with recurrent nonfatal VTE, post-thrombotic syndrome and fatal pulmonary embolism. ${ }^{1,2}$

Common risk factors for the development of DVT are prolonged immobilisation, surgery, leg trauma or fracture, plaster cast, paralysis or paresis, pregnancy or puerperium, hormone therapy, heart failure, long-distance travel, cancer, obesity, age, previous VTE, and smoking. ${ }^{3}$ Copur et al. reported that the human immunodeficiency virus (HIV) also increases the risk of VTE. ${ }^{4}$ In a retrospective review of patients with diagnosed DVT in an urban district in KwaZulu-Natal, South Africa, Awolesi et al. reported that HIV (51.85\%) and tuberculosis (TB) (35.80\%) were prevalent risk factors. ${ }^{5}$ Additional risk factors also reported in their study population were recent hospitalisation, smoking, previous DVT, and congestive heart failure.

The incidence of DVT in HIV-infected patients shows a two- to tenfold increase in comparison with a healthy population of similar age. ${ }^{6}$ The increased risk of venous thrombotic disease in HIV-infected patients could be explained by the presence of a hypercoagulable state, characterised by an increase in procoagulant factors and micro-particles, and a decrease in anticoagulant factors, including anti-thrombin III, heparin cofactor II, and the protein C pathway. ${ }^{6,7-9}$

HIV is a major public health concern worldwide. It is estimated that in 2015, 36.7 million people globally were living with HIV, 2.1 million became newly infected and 1.1 million had died of HIVrelated illnesses. ${ }^{10}$ According to the 2012 South African National HIV Prevalence, Incidence and Behaviour Survey, the total number of people in South Africa living with HIV in 2012 was approximately 6.4 million. ${ }^{11}$ An estimated $15.9 \%$ of South African adults aged 15 to 49 years are HIV-positive.

Data from studies done in the United States support the hypothesis that HIV-infected patients are more prone to clinically detected thromboembolic disease as compared with non-HIVinfected patients. Malek et al. examined a possible link between HIV infection and the presence of both pulmonary embolism and DVT. They reported that HIV-positive patients had statistically significant greater odds of $43 \%$ of developing a pulmonary embolism, $10 \%$ of developing DVT, and $40 \%$ of developing DVT or a pulmonary embolism. ${ }^{12}$ Copur et al. reported that HIVpositive patients under the age of 50 were at increased risk for VTE compared with HIV-negative patients in the same age range. $^{4}$

Studies have been done within the Southern Africa context to determine the association between HIV infection and DVT.8,9,11,13 A retrospective review of patients with confirmed DVT at an 
urban Cape Town public hospital reported a clear association between HIV, TB and the development of DVT. ${ }^{13}$ Some $64 \%$ of the patients were HIV-positive, $55.5 \%$ had TB, and $43.3 \%$ were positive for both HIV and TB.

Kimberley Hospital Complex (KHC) is a regional/tertiary hospital and the main referral centre in the Northern Cape. All patients presenting at $\mathrm{KHC}$ are triaged according to the Cape Triage score. ${ }^{14}$ Patients with suspected DVT are further assessed according to the Wells score system, which categorises the probability of DVT as high, moderate or low. ${ }^{15}$ Patients with a moderate to high probability of DVT are sent for a duplex Doppler ultrasound, while the D-dimer blood test is used to exclude DVT in low-risk patients. ${ }^{16}$

\section{Aim and objectives}

The aim of this study was to determine the presence of DVT risk factors and the prevalence of HIV infection in patients presenting to KHC who were diagnosed with DVT using a Doppler ultrasound. A further objective was to compare the demographics and risk factors of the HIV-positive and HIV-negative patients.

\section{Methods}

\section{Study design, sample and population}

This was a retrospective descriptive study with an analytic component. The sample included all patients who had undergone a Doppler ultrasound from January 2010 to December 2014 at the Department of Radiology, KHC, for suspected DVT. Patients with findings confirming DVT were included in the analysis.

\section{Data collection}

The ultrasound register at the Radiology Department was used to identify patients with suspected DVT. Files of patients with confirmed DVT were provided by the hospital's record department. Information was captured on a data sheet and included gender, age, HIV status, site(s) of DVT, risk factors and Wells score. The Wells score is used to determine the probability of DVT according to relevant clinical findings. A score of 3-8 points is indicative of a high probability of DVT, 1-2 points of a moderate probability and $-2-0$ of a low probability. ${ }^{15}$

If the HIV status results were not recorded in the patient's file, the main researcher attempted to locate the information from laboratory records.

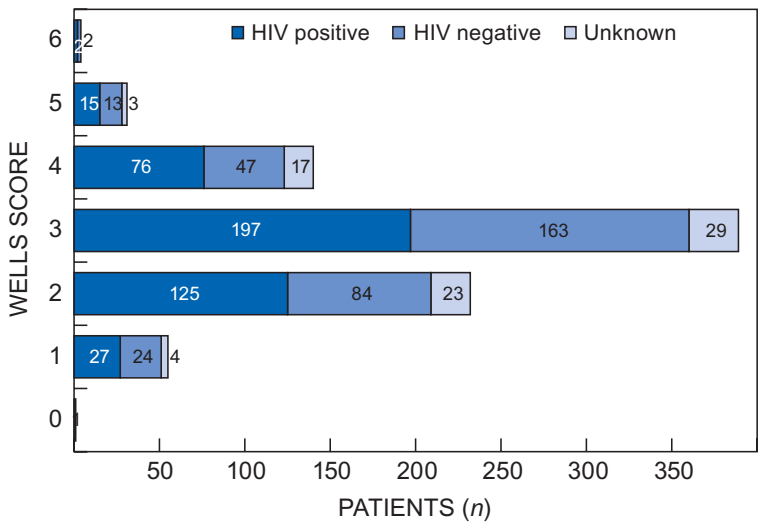

Figure 1: Distribution of Wells scores according to HIV status. Note: A score of 3-8 points $=$ high probability of DVT, 1-2 points $=$ moderate probability and $-2-0=$ low probability. ${ }^{15}$

\section{Pilot study}

A pilot study was conducted on 30 patients with confirmed DVT seen at KHC outside the study period to verify the feasibility of the study. Minor corrections were made to the data sheet. Data obtained from the pilot study were not included in the main study.

\section{Data analysis}

Data were analysed by the Department of Biostatistics, Faculty of Health Sciences of the University of the Free State (UFS). Descriptive statistics consisted of frequencies and percentages (categorical variables) and means and standard deviations or medians and percentiles (numerical variables, depending on data distribution). HIV-positive and -negative patients were compared using chi-square (categorical variables) and t-tests. An ANOVA was used to test the differences in age by HIV status.

\section{Ethical and legal considerations}

The study was approved by the Ethics Committees of the Faculty of Health Sciences, UFS (ECUFS 09/2015) and Northern Cape Provincial Department of Health (NCPHREC NC2015/007). Permission to access the ultrasound records was obtained from the Head, Department of Radiology and to access patient files from the Medical Director, KHC. Each patient was assigned a unique patient identifier to maintain confidentiality.

\section{Results}

\section{Demographic information}

From January 2010 to December 2014, 927 patients were diagnosed with DVT according to their Doppler ultrasound results. Of these patients, 852 (91.9\%) patient files were available for data analysis.

The majority of the patients were female ( $n=536,62.9 \%)$ and $316(37.1 \%)$ were male. The median age was 45 years (range 5-94 years, interquartile range 34-58 years). The highest percentage of patients (22.9\%) was 60 years and older. Patients in the age groups $0-14,15-19$ and 20-24 years accounted for only $6.9 \%$ of the study population. More than half $(n=443$, $52.0 \%)$ of the patients were HIV-positive, 333 (39.1\%) HIVnegative, while 76 (8.9\%) did not have a known HIV status.

The patients' Wells scores ranged between 0 and 6 , with a mean of 2.8 and a median of 3 (a score $\geq 3$ points is indicative of a high probability of DVT). Patients who were HIV-positive or HIVnegative both had mean scores of 2.8. Patients with unknown HIV status had a mean score of 2.9. Of the HIV-positive patients, $290(65.5 \%)$ had a score of $\geq 3$ compared with 225 (67.6\%) of the HIV-negative patients (Figure 1).

\section{Location of DVT}

All DVTs were present in the lower limbs of the patients. It was possible for patients to have DVT at multiple sites. Table 1 indicates the number of affected sites among patients diagnosed with DVT according to their HIV status with chi-square test $p$-values. The most affected sites overall were the left popliteal vein $(n=358,42.0 \%)$, left superficial femoral vein $(n=347,40.8 \%)$ and left common femoral vein ( $n=296,34.7 \%)$. The popliteal vein $(n=272,31.9 \%)$ and superficial femoral vein $(n=256,30.1 \%)$ were the sites most affected in the right limb.

HIV-positive patients and HIV-negative patients had a median of three affected sites (HIV-positive range: 1-10; HIV-negative 
Table 1: Number of DVTs in the different sites of patients' lower limbs overall and according to HIV status

\begin{tabular}{|c|c|c|c|c|c|}
\hline & \multirow[t]{2}{*}{ Total $(n=852)$} & \multicolumn{3}{|c|}{ HIV status } & \multirow{3}{*}{$\begin{array}{l}p \text {-values for HIV-positive } \\
\text { and -negative only }\end{array}$} \\
\hline & & HIV-positive $(n=443)$ & HIV-negative $(n=333)$ & Unknown $(n=76)$ & \\
\hline & $n(\%)$ & $n(\%)$ & $n(\%)$ & $n(\%)$ & \\
\hline \multicolumn{6}{|l|}{ Left: } \\
\hline Iliac vein & $152(17.8)$ & $75(16.9)$ & $61(18.3)$ & $16(21.1)$ & 0.63 \\
\hline Common femoral vein & $296(34.7)$ & $150(33.9)$ & $118(35.4)$ & $28(36.8)$ & 0.65 \\
\hline Profundus vein & $219(25.7)$ & $110(24.8)$ & $92(27.6)$ & $17(22.4)$ & 0.41 \\
\hline Popliteal vein & $358(42.0)$ & $188(42.4)$ & 132 (39.6) & $38(50.0)$ & 0.46 \\
\hline \multicolumn{6}{|l|}{ Right: } \\
\hline Iliac vein & $92(10.8)$ & $45(10.2)$ & $40(12.0)$ & $7(9.2)$ & 0.42 \\
\hline Common femoral vein & $203(23.8)$ & $104(23.5)$ & $88(26.4)$ & $11(14.5)$ & 0.36 \\
\hline Profundus vein & $153(18.0)$ & $78(17.6)$ & $67(20.1)$ & $8(10.5)$ & 0.40 \\
\hline Popliteal vein & 272 (31.9) & $152(34.3)$ & $103(30.9)$ & $17(22.4)$ & 0.35 \\
\hline
\end{tabular}

Notes: * Missing $n=1$.

Patients could have more than one affected site.

range: 0-9). There was no significant association between HIV status and location of the DVT site.

\section{Risk factors}

Risk factors noted in this study population included immobility (> 7 days), cancer, smoking, TB, previous DVT, pregnancy/ puerperium, heart failure, obesity (BMI $>30)$, recent surgery $(<$ 6 months), trauma/fracture/plaster cast, stroke/paralysis/paresis, long-distance travel (> $8 \mathrm{~h}$ ), the use of contraception, and thrombophilia.

Table 2 gives the occurrence of risk factors for DVT according to HIV status, with chi-square test $p$-values. The most frequent risk factors in the study population overall were TB $(n=106,12.4 \%)$, followed by cancer ( $n=93,10.9 \%)$, and smoking ( $n=77,9.0 \%$ ). Pregnancy/puerperium also showed a high frequency in the female subgroup ( $n=64 / 536,11.9 \%$ ). Thrombophilia and longdistance travel were the risk factors with the lowest occurrence ( $n=3,0.4 \%$ each).

The main risk factors for HIV-positive patients were TB $(n=85$, $19.2 \%)$, smoking $(n=39,8.8 \%)$, cancer $(n=37,8.4 \%)$, and previous DVT ( $n=33,7.5 \%)$. Risk factors for HIV-negative patients were mainly cancer $(n=48,14.4 \%)$, immobility $(n=47,14.1 \%)$, pregnancy/puerperium ( $n=31,13.9 \%)$, and previous DVT $(n=26,7.8 \%)$.

Table 2: Prevalence of risk factors for DVT in patients seen at Kimberley Hospital Complex

\begin{tabular}{|c|c|c|c|c|c|}
\hline \multirow[t]{3}{*}{ Factor } & \multirow{3}{*}{$\begin{array}{c}\text { Total }(n=852) \\
n(\%)\end{array}$} & \multicolumn{3}{|c|}{ HIV status } & \multirow{3}{*}{$\begin{array}{c}p \text {-values for HIV-positive } \\
\text { and -negative only }\end{array}$} \\
\hline & & HIV positive $(n=443)$ & HIV negative $(n=333)$ & Unknown $(n=76)$ & \\
\hline & & $n(\%)$ & $n(\%)$ & $n(\%)$ & \\
\hline Tuberculosis (TB) & $106(12.4)$ & $85(19.2)$ & $19(5.7)$ & $2(2.6)$ & $<0.01$ \\
\hline Cancer & $93(10.9)$ & $37(8.4)$ & $48(14.4)$ & $8(10.5)$ & 0.01 \\
\hline Smoking & $77(9.0)$ & $39(8.8)$ & $23(6.9)$ & 15 (19.7) & 0.33 \\
\hline Immobility & $74(8.7)$ & $25(5.6)$ & $47(14.1)$ & $2(2.6)$ & $<0.01$ \\
\hline $\begin{array}{l}\text { Previous deep vein thrombo- } \\
\text { sis (DVT) }\end{array}$ & $67(7.9)$ & $33(7.5)$ & $26(7.8)$ & $8(10.5)$ & 0.85 \\
\hline Pregnancy/puerperium ${ }^{* *}$ & $64(11.9)^{*}$ & $27(10.0)$ & $31(13.9)^{*}$ & $6(13.6)$ & 0.18 \\
\hline Heart failure & $34(4.0)$ & $16(3.6)$ & $17(5.1)$ & $1(1.3)$ & 0.31 \\
\hline Obesity & $31(3.6)$ & $18(4.1)$ & $9(2.7)$ & $4(5.3)$ & 0.31 \\
\hline Recent surgery & $26(3.1)^{*}$ & $9(2.0)^{*}$ & $11(3.3)$ & $6(7.9)$ & 0.27 \\
\hline Trauma/fracture & $19(2.2)$ & $6(1.4)$ & $11(3.3)$ & $2(2.6)$ & 0.07 \\
\hline Stroke/paralysis/paresis & $14(1.6)$ & $4(0.9)$ & $9(2.7)$ & $1(1.3)$ & 0.05 \\
\hline Oral contraception ${ }^{* *}$ & $5(0.9)$ & $1(0.3)$ & $4(1.8)$ & $0(0)$ & 0.18 \\
\hline Thrombophilia & $3(0.4)$ & $0(0)$ & $2(0.6)$ & $1(1.3)$ & 0.18 \\
\hline Long-distance travel & $3(0.4)$ & $2(0.5)$ & $0(0)$ & $1(1.3)$ & 0.51 \\
\hline
\end{tabular}

Notes: *Missing $n=1$; **Results representative of female patients $(n=536)$ only.

Patients could have more than one risk factor. 


\section{HIV prevalence}

The yearly percentage of patients with unknown HIV status among the patients with DVT varied from $18.4 \%$ in 2010 to $3.9 \%$ in 2013. Of patients with known HIV status, the HIV prevalence ranged between $52.9 \%$ in 2014 and $64.7 \%$ in 2010 (Figure 2).

In both the male and female patients, at least $50 \%$ were HIVpositive (Table 3). As presented in Table 4, the highest percentage of HIV-positive male patients (17.2\%) was in the age group 3539 years and HIV-positive female patients (19.0\%) in the age group 30-34 years. The highest percentage of both HIV-negative male and female patients was 60 years and older $(44.6 \%$ and $38.1 \%$, respectively). An ANOVA ( $F=54.75, \mathrm{df}=2, p<0.0001$ ) with post hoc Scheffé tests showed that the ages of all three groups differed significantly, with the HIV-negative patients having a mean age of 53.1 years, the HIV-positive patients a

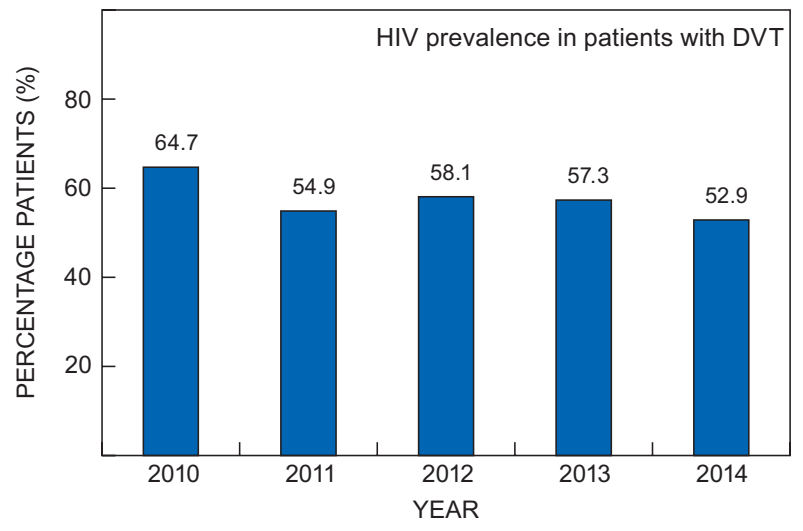

Figure 2: Prevalence of HIV among patients with DVT where patients with unknown HIV status are excluded.

Table 3: HIV status by gender

\begin{tabular}{lcc}
\hline HIV status & Male $(n=316)$ & Female $(\boldsymbol{n}=536)$ \\
& $n(\%)$ & $n(\%)$ \\
\hline Positive & $174(55.1)$ & $269(50.2)$ \\
Negative & $110(34.8)$ & $223(41.6)$ \\
Unknown & $32(10.1)$ & $44(8.2)$ \\
\hline
\end{tabular}

mean age of 41.3 years, and those with an unknown HIV status a mean age of 47.3 years.

In Figure 3, the age distribution according to HIV status is displayed.

\section{Discussion}

In this study, $62.9 \%$ of the patients with DVT were female compared with $37.1 \%$ who were male patients. Awolesi et al. had a similar gender distribution with a majority of females in their sample, based on hospital admissions. ${ }^{5}$ Their study, however, showed a slightly younger female population affected by DVT. The highest percentage of HIV-positive female patients with DVT were in their early thirties while HIV-positive males were in their late thirties. HIV-negative patients with DVT were mostly in their sixties.

It is not clear whether the preponderance of females in the sample is due to hormonal or gender factors, or is a reflection of differing health service usage by the genders. Statistics South Africa reported that more women attend health facilities than men to seek help in the early stage of their illness. The men believed that their illness was not serious enough to warrant care. $^{17}$

The findings of this study and those of Awolesi et al. are surprisingly similar in the prevalence of HIV in the DVT-proven populations. ${ }^{5}$ The prevalence of HIV in the DVT patients was much higher than the prevalence of the 'general admitted population' at KHC and the general Northern Cape population. According to the 2012 South African National HIV Prevalence, Incidence and Behaviour Survey, the prevalence of HIV in South Africa is $12.2 \% .^{11}$ This prevalence varies among provinces, with KwaZulu-Natal the highest at $16.9 \%$ and the Western Cape and Northern Cape the lowest at $5.0 \%$ and $7.4 \%$, respectively.

An audit by Louw et al. at a hospital in Johannesburg reported an HIV prevalence of $84 \%$ in patients presenting with DVT. ${ }^{9}$ Olubanwo reported a prevalence of $79.4 \%$ in a retrospective study on all DVT cases admitted to a hospital in Mthatha over a one-year period. ${ }^{18}$ Our results as well as the literature show that HIV prevalence in DVT patients is higher compared with the prevalence of HIV in the general population. ${ }^{6}$ The high prevalence of HIV among known DVT patients may well indicate that the relative risk of developing DVT when being HIV-positive is much higher than in the HIVnegative group, as shown by Govender et al..$^{19}$

Table 4: HIV status by age group and gender

\begin{tabular}{|c|c|c|c|c|c|c|c|}
\hline \multirow[t]{2}{*}{ Age group (years) } & \multirow{2}{*}{$\begin{array}{c}\text { Total }(n=852) \\
n(\%)\end{array}$} & \multicolumn{2}{|c|}{ HIV-positive ( $n=443)$} & \multicolumn{2}{|c|}{ HIV-negative $(n=333)$} & \multicolumn{2}{|c|}{ Unknown $(n=76)$} \\
\hline & & $\begin{array}{l}\text { Male } \\
n(\%)\end{array}$ & $\begin{array}{c}\text { Female } \\
n(\%)\end{array}$ & $\begin{array}{l}\text { Male } \\
n(\%)\end{array}$ & $\begin{array}{c}\text { Female } \\
n(\%)\end{array}$ & $\begin{array}{l}\text { Male } \\
n(\%)\end{array}$ & $\begin{array}{c}\text { Female } \\
n(\%)\end{array}$ \\
\hline $0-14$ & $4(0.5)$ & $1(0.6)$ & $0(0)$ & $2(1.8)$ & $1(0.5)$ & $0(0)$ & $0(0)$ \\
\hline $15-19$ & $19(2.2)$ & $2(1.2)$ & $3(1.1)$ & $1(0.9)$ & $12(5.4)$ & $0(0)$ & $1(2.3)$ \\
\hline $20-24$ & $36(4.2)$ & $5(2.9)$ & $11(4.1)$ & $2(1.8)$ & $15(6.7)$ & $0(0)$ & $3(6.8)$ \\
\hline $25-29$ & $71(8.3)$ & $20(11.5)$ & $27(10.0)$ & $3(2.7)$ & $17(7.6)$ & $2(6.3)$ & $2(4.6)$ \\
\hline $30-34$ & $102(12.0)$ & $29(16.7)$ & $51(19.0)$ & $7(6.4)$ & $6(2.7)$ & $3(9.4)$ & $6(13.6)$ \\
\hline $35-39$ & $98(11.5)$ & $30(17.2)$ & $41(15.2)$ & $6(5.5)$ & $13(5.8)$ & $4(12.5)$ & $4(9.1)$ \\
\hline $40-44$ & $86(10.1)$ & $21(12.1)$ & $40(14.9)$ & $4(3.6)$ & $12(5.4)$ & $4(12.5)$ & $5(11.4)$ \\
\hline $45-49$ & $97(11.4)$ & $26(14.9)$ & $31(11.5)$ & $12(10.9)$ & $22(9.9)$ & $3(9.4)$ & $3(6.8)$ \\
\hline $50-54$ & $83(9.7)$ & $13(7.5)$ & $27(10.0)$ & $14(12.7)$ & $19(8.5)$ & $4(12.5)$ & $6(13.6)$ \\
\hline 55-59 & $61(7.2)$ & $9(5.2)$ & $14(5.2)$ & $10(9.1)$ & $21(9.4)$ & $2(6.3)$ & $5(11.4)$ \\
\hline $60+$ & 195 (22.9) & $18(10.3)$ & $24(8.9)$ & 49 (44.6) & $85(38.1)$ & $10(31.3)$ & $9(20.5)$ \\
\hline
\end{tabular}




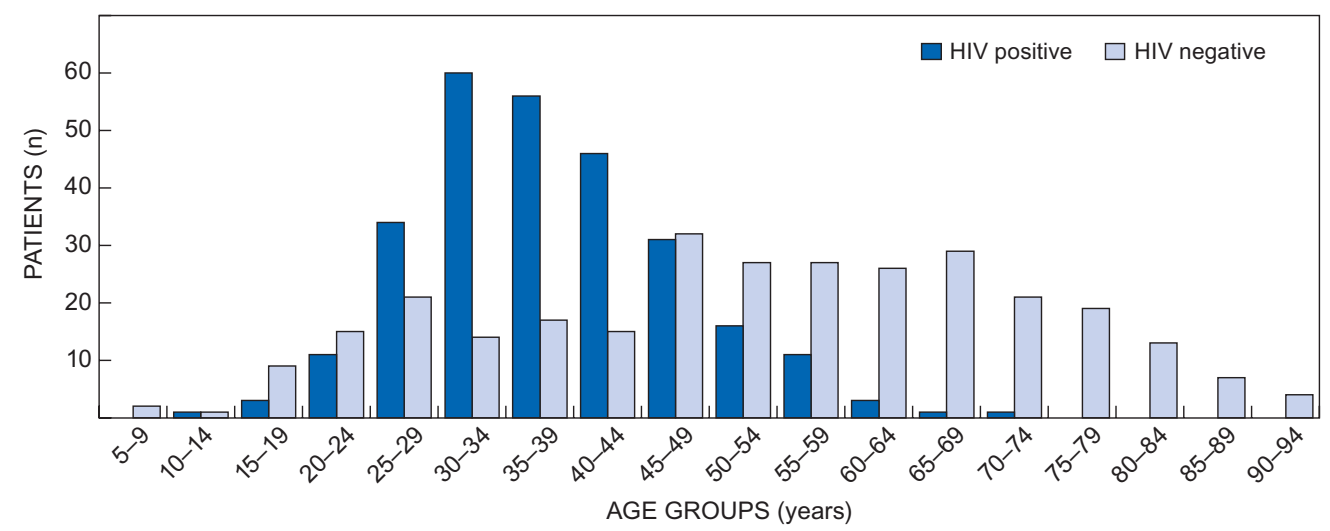

Figure 3: Age distribution of patients with DVT by known HIV status.

Previous studies have also shown the association between HIV and VTE (DVT).,16 The HIV infection being a prothrombotic condition, multiple factors have been described as of HIV-related venous thromboembolism aetiology., ${ }^{42,20}$

It was recognised 20 years ago that HIV disease causes a prothrombotic condition but little evidence is known regarding the mechanism. ${ }^{21} \mathrm{~A}$ study by Jong et al. showed that initiation of antiretroviral therapy improves the markers of endothelial cell activation, coagulation and natural anticoagulation in South African HIV-infected individuals.22 A similar study done in Denmark confirmed the result and demonstrated the improvement in cardiovascular risk. ${ }^{23}$

There has been some decline in HIV prevalence in patients with DVT at KHC during the five-year study period, dropping from $64.7 \%$ in 2010 to $52.9 \%$ in 2014 . However, this is still high compared with the prevalence of HIV among patients admitted to $\mathrm{KHC}$ during the same period, which ranged between $7.0 \%$ and $10.9 \% .^{24}$

Considering the Wells score as measured in this study, the mean Wells scores for HIV-positive, HIV-negative and HIV status unknown patients were similar and indicative of a high probability of DVT. This is not surprising, as the sample consisted only of confirmed DVT cases. It is, in fact, more troublesome that close on a third of the Wells scores for confirmed DVT cases were below 3 , which is the cut-off value for a high probability of DVT. However, most of those cases below 3 were either 1 or 2, which indicates a moderate likelihood of DVT, and only one case had a score of zero. It has been demonstrated by Oudega et al. that the Wells score might be inadequate in the primary care setting, although in a tertiary hospital such as KHC this should be less of a problem. ${ }^{25}$ In this study, however, the selection of confirmed DVT cases (with their attendant high Wells scores) does not preclude the idea of considering HIV infection as an independent risk factor for DVTs.

For all of the DVT sites, no statistical difference was found. All of the patients in this study had DVT in their lower limbs, which confirms findings in the literature. ${ }^{26,27}$ Labropoulos et al. also reported that lower extremity DVT is more prevalent in hospitalised patients, and is associated with significant shortand long-term morbidity and mortality. ${ }^{27}$

Some studies give prominence to the left lower limb as a DVT site. Ouriel et al. reported that DVT was more common on the left side, and speculated that it was due to left common iliac vein involvement. ${ }^{26}$ In comparison, this study showed that the left popliteal vein was the most affected site $(42.0 \%)$ followed by the left superficial femoral vein and left common femoral vein $(40.8 \%$ and $34.7 \%$, respectively). There was no evidence that the sites of the DVT were directly affected by the HIV status of the patients. This finding is also reported by Sule et al. ${ }^{28}$

Most of the 'classic' risk factors seen in DVT cases were present in our study sample. Cancer was recorded in $10.9 \%$ of the cases. Heit et al. reported malignancies as an independent risk factor for VTE. ${ }^{29}$ Similar results were reported by Samama. ${ }^{30}$ In our study, cervical and breast cancer were more commonly found malignancies, although not specified in the results. Cancer is a considerable risk factor for DVT as demonstrated in the literature. ${ }^{29,30}$ Our study showed that cancer and immobility were more prevalent in the HIV-negative patients than in the HIVpositive patients. The other risk factors did not appear to be affected by the HIV status.

Smoking occurred as the fourth most frequent risk factor for DVT in our study. Hansson et al. reported that smoking and obesity independently increase the risk for DVT. ${ }^{31}$ Pungpapong et al. reported that smoking increases the incidence of vascular complications. ${ }^{32}$ In comparison, Prescott et al. reported that rising levels of cigarette smoking were associated with a lower incidence of DVT. ${ }^{33}$

TB was found to be common among the patients with diagnosed DVT at $12.4 \%$. Robson et al. demonstrated that DVT caused by TB is most probably due to the increase in plasma fibrinogen with impaired fibrinolysis and a decrease in anti-thrombin $111 .{ }^{34}$ According to Alshehri et al., this may be related to the high prevalence of TB in South Africa and the strong association between TB and HIV. ${ }^{13}$

\section{Limitations}

As this was a retrospective study, data of patients with confirmed DVT by Doppler ultrasound were obtained from the ultrasound register and patient files, and blood results from the laboratory database. This study depended on the quality of the data recorded. There were files without mention of risk factors and several without the patient's HIV results.

\section{Conclusion}

This study found a prevalence of HIV infection in more than half of patients with DVT admitted to KHC over a five-year period. Over the same period, the reported KHC prevalence of patients with HIV ranged between $7.0 \%$ and $10.9 \%$. The data also showed 
that HIV-positive patients with TB as a co-morbidity had the highest prevalence of DVT. This pattern was not seen in HIVpositive patients with other risk factors, such as cancer and the use of oral contraception.

\section{Recommendations}

Results from this study can be used by KHC to compile standard operating procedures and allocate resources related to the management of DVT and associated co-morbidities. The strong association of HIV infection and VTE needs to be noted.

Doctors working in primary healthcare settings should be trained in the prompt diagnosis and early management of DVT considering HIV as an important factor of risk.

The authors recommend that HIV counselling and testing be made policy for all patients diagnosed with DVT.

Disclosure statement - No potential conflict of interest was reported by the authors.

Funding - None.

Acknowledgements - The authors wish to express sincere thanks and appreciation towards the following persons: Prof G Joubert, Department of Biostatistics, Faculty of Health Sciences, UFS, for her rigorous statistical support, $\mathrm{Dr} \mathrm{T}$ Habib and $\mathrm{Dr} \mathrm{H}$ Saeed, Family Medicine, $\mathrm{KHC}$, for supporting and guiding the project, $\mathrm{Dr}$ A Fayyaz, Internal Medicine, KHC, for supporting the project, the management and staff of the Record Department at KHC for allowing us to search through the files, and Ms T Mulder, medical editor, School of Medicine, UFS, for technical and editorial preparation of the manuscript.

\section{ORCID}

WJ Steinberg (iD) http://orcid.org/0000-0001-9944-1807 JE Raubenheimer (ID) http://orcid.org/0000-0003-3907-304X

\section{References}

1. Douketis JD, Kearon C, Bates S, Duku EK, Ginsberg JS. Risk of fatal pulmonary embolism in patients with treated venous thromboembolism. JAMA 1998;279(6):458-62. doi:10.1001/ jama.279.6.458.

2. Blann $A D$, Khoo CW. The prevention and treatment of venous thromboembolism with LMWHs and new anticoagulants. Vasc Health Risk Manag. 2009;5:693-704. https://doi.org/10.2147/VHRM.

3. Bernardi $E$, Camporese $G$, Büller $H R$, et al. Serial 2-point ultrasonography plus D-dimer vs whole-leg color-coded Doppler ultrasonography for diagnosing suspected symptomatic deep vein thrombosis: a randomized controlled trial. JAMA 2008;300(14):16539. doi:10.1001/jama.300.14.1653.

4. Copur AS, Smith PR, Gomez V, et al. HIV infection is a risk factor for venous thromboembolism. AIDS Patient Care STDs 2002;16(5):205-9. doi:10.1089/10872910252972258.

5. Awolesi $\mathrm{D}$, Naidoo $\mathrm{M}$, Cassimjee $\mathrm{MH}$. The profile and frequency of known risk factors or comorbidities for deep vein thrombosis in an urban district hospital in KwaZulu-Natal. S Afr J HIV Med. 2016;17(1):a425. doi:10.4102/sajhivmed.v17i1.425.

6. Klein SK, Slim EJ, de Kruif MD, et al. Is chronic HIV infection associated with venous thrombotic disease? A systematic review. Neth J Med. 2005:63(4):129-36.

7. Saif MW, Greenberg B. HIV and thrombosis: a review. AIDS Patient Care STDs 2001;15(1):15-24. doi:10.1089/108729101460065.

8. Bassa FC. Coagulation system abnormalities in human immunodeficiency virus (HIV) positive African (Black) patients with acute upper segment deep vein thrombosis (DVT) of the lower limbs. Durban, South Africa: University of KwaZulu-Natal; 2006. [cited
2017 June 01]. Available from: https://researchspace.ukzn.ac.za/ handle/10413/573.

9. Louw S, Jacobson BF, Büller H. Human immunodeficiency virus infection and acute deep vein thromboses. Clin Appl Thromb Hemost. 2008;14(3):352-5. doi:10.1177/1076029607304411.

10. World Health Organization. Global health observatory (GHO) data. Size of the epidemic. Geneva: WHO; 2015. [cited 2017 June 01]. Available from: http://www.who.int/gho/hiv/epidemic_status/en/.

11. Shisana O, Rehle T, Simbayi LC, et al. South African national HIV prevalence, incidence and behaviour survey, 2012. Cape Town, South Africa: Human Sciences Research Council; 2014.

12. Malek J, Rogers R, Kufera J, et al. Venous thromboembolic disease in the HIV-infected patient. Am J Emerg Med. 2011;29(3):278-82. doi:10.1016/j.ajem.2009.09.034.

13. Alshehri MF. Risk factors for deep vein thrombosis in a South African public hospital. Cape Town, South Africa: University of Cape Town; 2013. [cited 2017 February 28]. Available from: http://hdl.handle. net/11427/2879.

14. Wallis PA, Gottschalk SB, Wood D, et al. The cape triage score-a triage system for South Africa. S Afr Med J. 2006;96(1):53-6.

15. Wells PS, Hirsh J, Anderson DR, et al. A simple clinical model for the diagnosis of deep-vein thrombosis combined with impedance plethysmography: potential for an improvement in the diagnostic process. J Intern Med. 1998;243(1):15-23. doi:10.1046/j.13652796.1998.00249.x

16. Kearon C, Kahn SR, Agnelli G, et al. Antithrombotic therapy for venous thromboembolic disease: American College of Chest Physicians Evidence-Based Clinical Practice Guidelines (8th Edition). Chest 2008;133(6 Suppl):454S-545S. doi:10.1378/chest.08-0658.

17. Statistics South Africa. Use of health facilities and levels of selected health conditions in South Africa: Findings from the General Household Survey, 2011. Pretoria, South Africa: Statistics South Africa; 2013. [cited 2017 June 01]. Available from: http://www.statssa. gov.za/publications/Report-03-00-05/Report-03-00-052011.pdf.

18. Olubanwo O. The profile of HIV/AIDS patients admitted with deep vein thrombosis (DVT) at Nelson Mandela Hospital in Mthatha. Afr J Prim Health Care Fam Med. South Africa. Abstract; 2010. Available from: http://www.phcfm.org/index.php/phcfm/thesis/view/32.

19. Govender I, Mabuza HL, Ogunbanjo GA. The characteristics of HIV and AIDS patients with deep vein thrombosis at Dr. George Mukhari Academic Hospital. Afr J Prim Health Care Fam Med. 2015;7(1):1-3. doi:10.4102/phcfm.v7i1.690.

20. Saber AA, Aboolian A, LaRaja RD, et al. HIV/AIDS and the risk of deep vein thrombosis: a study of 45 patients with lower extremity involvement. Am Surg. 2001;67(7):645-7.

21. Eyal A, Veller M. HIV and venous thrombotic events. S Afr J Surg. 2009;47(2):54-6.

22. Jong $E$, Louw S, van Gorp EC, et al. The effect of initiating combined antiretroviral therapy on endothelial cell activation and coagulation markers in South African HIV-infected individuals. Thromb Haemost. 2010;104(6):1228-34. doi:10.1160/TH10-04-0233.

23. Arildsen $\mathrm{H}$, Sørensen $\mathrm{KE}$, Ingerslev JM, et al. Endothelial dysfunction, increased inflammation, and activated coagulation in HIV-infected patients improve after initiation of highly active antiretroviral therapy. HIV Med. 2013;14(1):1-9. doi:10.1111/j.1468-1293.2012.01027.x.

24. Kimberley Hospital Complex. Kimberley hospital complex statistics 2010-2014. Unpublished internal document. 2014

25. Oudega R, Hoes AW, Moons KG. The wells rule does not adequately rule out deep venous thrombosis in primary care patients. Ann Intern Med. 2005;143(2):100-7. doi:10.7326/0003-4819-143-2-20050719000008.

26. Ouriel K, Green RM, Greenberg RK, et al. The anatomy of deep venous thrombosis of the lower extremity. J Vasc Surg. 2000;31(5):895-900. doi:10.1067/mva.2000.105956.

27. Labropoulos N, Bekelis K, Leon LR Jr. Thrombosis in unusual sites of the lower extremity veins. J Vasc Surg. 2008;47(5):1022-7. doi:10.1016/j. jvs.2007.12.044.

28. Sule AA, Pandit N, Handa P, et al. A case series of HIV-seropositive patients and hypercoagulable state - is it difficult to treat even with therapeutic anticoagulation? Int J Angiol. 2013;22(2):105-8. doi:10.1 055/s-0033-1334868 
29. Heit JA, Silverstein MD, Mohr DN, et al. Risk factors for deep vein thrombosis and pulmonary embolism: a population-based casecontrol study. Arch Intern Med. 2000;160(6):809-15. doi:10.1001/ archinte.160.6.809.

30. Samama MM. An epidemiologic study of risk factors for deep vein thrombosis in medical outpatients: the Sirius study. Arch Intern Med. 2000;160(22):3415-20. doi:10.1001/archinte.160.22.3415.

31. Hansson PO, Eriksson $\mathrm{H}$, Welin L, et al. Smoking and abdominal obesity: risk factors for venous thromboembolism among middleaged men: "the study of men born in 1913". Arch Intern Med. 1999;159(16):1886-90. doi:10.1001/archinte.159.16.1886.
32. Pungpapong S, Manzarbeitia C, Ortiz J, et al. Cigarette smoking is associated with an increased incidence of vascular complications after liver transplantation. Liver Transpl. 2002;8(7):582-7. doi:10.1053/ jlts.2002.34150.

33. Prescott RJ, Jones DR, Vasilescu C, et al. Smoking and risk factors in deep vein thrombosis. Thromb Haemost. 1978;40(1):128-33.

34. Robson SC, White NW, Aronson I, et al. Acute-phase response and the hypercoagulable state in pulmonary tuberculosis. Br J Haematol. 1996;93(4):943-9. doi:10.1046/j.1365-2141.1996.d01-1722.x.

Received: 22-08-2017 Accepted: 14-01-2018 